\title{
Experiences of Creative Industries Development in Developed Countries and Enlightenments
}

\author{
Hongman Zhang \\ Changchun University of Science \& Technology, Changchun 130022, China \\ E-mail: zhanghm1995@163.com \\ Jing Wang \\ Changchun University of Science \& Technology, Changchun 130022, China \\ Di Liu \\ Changchun University of Science \& Technology, Changchun 130022, China
}

Received: April 5, $2011 \quad$ Accepted: April 28, $2011 \quad$ doi:10.5539/ass.v7n8p237

Subject Source: Social Sciences Foundation Item in Jilin Province, March 2010

\begin{abstract}
UK, USA, and Germany have relatively advanced creative industries with different characteristics. In this paper, authors try to summarize experiences of developing creative industries in developed countries and put forward strategies for China developing creative industry.

Keywords: Creative industries, Industry chain, Pattern of economic growth

For creative industries, an internationally-accepted definition is: "those industries which have their origin in individual creativity, skill and talent and which have a potential for wealth and job creation through the generation and exploitation of intellectual property." Creative industries are newly- emerging industries which combine cutting-edge technological products and cultural art creativity together, comprising thirteen industries, such as art, film, advertising, agriculture, and design. Statistical data show that creative economy generates the value of 22 billion UA dollars every year in the world, and the number rises at the rate of 5\% above. The annual growth rate of creative industries in USA is $14 \%$, and in UK is $12 \%$. Many countries and regions, such as UK, USA, Germany, Singapore, and Japan, have creative industries as backbone industries.

Creative industries just start the development in China. Currently, Shanghai, Guangzhou, and other cities are engaged in researching and practicing cultural creative industries. The power for development is strong. It is predicable that creative industries would play a more important role in comprehensive and coordinative economic development in China and further adjustment of industrial structure.

We should find out a way to develop creative industries in China by learning from experiences of developed countries and knowing the characteristics of China economy.

\section{The comparative analysis of creative industries in world main developed countries}

Creative industries initially emerge in developed countries, which results in developed creative industries in these countries. Their common characteristics are positive environmental basis, deep cultural roots, strong economic powers, and advanced science and technology.

\subsection{The country that firstly advanced the concept of "creative industries" ------ UK}

The concept of creative industries initially emerged in UK. At that time in UK, many old industrial cities developed at a low speed. The manufacture industry consumed lots of energies, produced serious pollutions, with low added values, losing their competency. UK government and citizens were eager to find a new economic growth point in order to improve the long-term economic stagnation. Then, creative industries came into being. By the year 2000, creative industries have become the No.2 backbone industries right behind the financial service industry. Therefore, UK has amounts of experiences in this field.
\end{abstract}


(1) The strong support from the government. In order to better develop the creative industries, the UK has released the creative industries agenda twice, respectively in 1998 and 2001, analyzing the current development of creative industries and the development strategy. Besides, the UK government has established a national "creative industries committee", which is responsible for organizing and coordinating the development of creative industries in UK. The committee is to constitute the blueprint of creative industries development, plan the industrial policies of creative industries, distribute budgets, and allocate creative industries funds. Accordingly, local governments set up local agencies for directing the development of creative industries. The government purchases services from intermediary organizations by all means, what will promote creative products in market. Gradually, it becomes a win-win business activity for market, state, enterprise, and individual.

In order to improve the international exchange in the field of creative industries, the UK has begun to host the "London Design Festival" and the "World Forum on Creative Industries" since the year 2003, which makes the UK a country leading the world creative fashion.

(2) The systematic sorting of industry sectors. The Cultural creative industries in UK have mature environmental base, proper operation mechanism, and complete industrial structure. In addition, the selected industries are relatively more mature. Therefore, all industrial sectors can support and supply with each other, forming a whole complete industry chain.

Creative industries not only bring about 7\% contribution ratio to GDP, but also generate driving forces for other industries, as well as influence all aspects of life. Materials from UK Trade \& Investment show that in 2005 creative industries have supplied more than 1.8 million jobs.

\subsection{The country that has the most developed creative industries ------ USA}

In the United States, creative industries depend on two driving forces. The first is culture communication, which is based on developed economic mode. And it has been a fashion, such as Barbie doll, Hollywood, jeans, etc. The other is the innovation in technological field, represented by Google, Microsoft, and Boeing. Although the U.S. government has not released any official policy file for the development of creative industries, creative industries have become the largest and most dynamic industries in U.S., generating considerable economic profits.

(1) Obvious tendency of forming groups and agglomerations. Along with the economic globalization, political multi-polarization and cultural diversity in the world, creative industries is becoming more competitive. It is clear that creative enterprises tend to form groups or agglomerations. Take the media market for example. United States control $75 \%$ global TV market. AOL-Time Warner possesses 13 billion cable subscribers from former Time Warner and 20 million Internet users from former AOL. It is a media giant, providing interactive information and amusement by global network communication, and using computer multimedia platform. Disney successfully changed its business focus from theme parks to film and TV at early $90 \mathrm{~s}$ in $20^{\text {th }}$ century, becoming a complex giant. The development of creative industries and the growth of industry chain usually produce industrial agglomeration and optimized combination of resources, forming advantages of scale. As a result, it improves the abilities of R\&D and production, and the overall strength of culture creative industries. Creative industries comprise not only creative production activities and traditional service industries, but also spiritual and psychological service industries, such as culture, art, entertainment, and leisure. Creative Park is a manifestation of spatial agglomeration of creative industries.

(2) Perfect legislation. United States has always attached great importance to intellectual property right protection. United States has set up administrative departments, including United States Trade Representative, International Trade Administration, and Copyright Office, and direct official work teams, such as the Clinton Administration's "Information Policy Committee", and "National Information Infrastructure Advisory Committee", in order to strengthen the supervision and protection for copyright. The U.S. government has approved the "Copyright Law", "Electronic Piracy Prohibition Act", "Cross-Century Digital Copyright Law", "Semi-Conductor Chip Protection Law", and other series of protection laws, which gives United States the most detailed legal system covering the widest range of protection. During recent years, U.S. continues to amend relevant copyright laws and improve the copyright protection system, constituting lots of legislative proposals including database protection, and providing legal guarantee for the prosperity of copyright industries.

\subsection{The country with the most charming creative industries ------ Germany}

Early in 1912, the German economic thinker Schumpeter pointed out: "The fundamental driving force for modern economic development is not capital or labor, but innovation." In Germany, some social communities and organizations, such as "Creative Berlin", came into being. In 2009, some Germany journals published special albums to introduce Germany creative industries. German Ministry of Foreign Affairs printed the 
calendar to introduce creative industries in different languages and spread it among other countries.

(1) Historic opportunity. In Germany, some places become bases for creative industries, because they reflect traditional culture and integrate modern fashion elements. In 2004, the EU extended toward the east. Its population rises by 100 million, and business opportunities are numerous, what has a strategic significance in Germany. During recent years, almost all cultural creative industries are open to investment. More and more international business groups move in Germany, including many cultural creative industries giants. Objectively, it promotes the development of cultural creative industries. Take the music industry for example. Industry giants Sony Music and Universal Music Group have entered Berlin one after another. BMG and EMI, the two record companies have set up offices in Berlin. Again, Germany has carried out a very detailed planning for the repair of old buildings and technological infrastructure. Especially in the transformation of old city, Germany is extremely carful at each step. All programs should be discussed before being released in public. Therefore, Germany has built a good technological base for the development of cultural creative industries, especially the media, electronic publications, film and television produce industries.

(2) Cultural diversity. The respect for innovation and personality, the dynamic culture circle, and the artistic atmosphere are inevitable motivating elements for the development of creative industries in Germany. Berlin is the largest city in Germany, and also a world-class cultural metropolis. It offers living spaces for various life styles. About 500,000 foreigners from 185 countries, $13 \%$ of total population, live in Berlin. Take music for example. In Berlin, there are ten well-known bands (including the world-renowned Berlin Philharmonic Orchestra), one hundred classical music performance groups, and nearly one thousand rock pop bands. Everyday, there are about 1500 different cultural activities in Berlin. It is not surprising for Berlin being a first-class international cultural metropolis.

(3) Human resource. Emphasize on the cultivation of design talents. In Germany, many cities have first-class art institutions to train high-level art talents. They have top-notch technical facilities and teachers, cultivating a large batch of high-tech talents for creative industries.

Focus on attracting talents. Free artistic atmosphere and people's high attentions to arts attract artists from around the world. All kinds of creative talents, such as photographers, fashion designers, and architects, can find excellent infrastructure and living space easily. Amounts of artists provide an endless source for the development of creative industries in Germany. And the development of creative industries brings about considerable income for artists.

\section{Measures for developing creative industries in China}

Currently, the advertising industry in China is growing into the largest market in the world. And data show that the annual output of China's animation industry exceeds 18 billion RMB. However, compared with developed countries or cities, the development of creative industries in China is still in its infancy. The gap is still very obvious.

(1) From the national strategic level, we should enhance the recognition to the importance and urgency of developing creative industries. The development of creative industries needs a more explorative theory as the guidance. UK, Singapore, and Australia have promulgated strategies for developing creative industries, establishing its short-term and long-term plans, in order to actively promote the development of creative industries, improving the international competitiveness of one country or region. Therefore, in order to develop creative industries, firstly the society should improve the understanding and recognition to the importance, cutting edge character, and future tendency of development of creative industries. Secondly, decision makers at all levels should further establish the key industry in support, make general industry planning, build a legal supportive system, develop the policy guidance for future development, optimize the internal and external environment for the development of creative industries, deeply explore and learn advanced experiences and methods from other countries in developing creative industries.

(2) Talents are the core competitiveness of creative industries. Creative industries are people-oriented. To educate and cultivate a batch of creative talents are the prerequisite for the fast development of creative industries in future. In China, the bottleneck of developing creative industries is the shortage of creative talents. Reports show that talents in creative industries account for $12 \%$ of total employment in New York, and the percentage is $14 \%$ in London, $15 \%$ in Tokyo, and less than $1 \%$ in Shanghai. Currently, the human resources in China are far from satisfying the needs for fast development of creative industries. Now we not only lack top creative talents and planning talents, but also face a problem of few original works and creative modes. Particularly, we lack business talents and marketing talents who are good at promoting creative works in market. Therefore, we must create a new training mechanism, cultivate and introduce kinds of creative talents, cultural brokers, and intermediaries, in order to transform creative works into business resources, promoting the healthy 
and fast development of creative industries in China.

(3) Provide policy supports for funding, taxation, investment and financing. From experiences of developed countries in developing creative industries, creative industries can not develop without strong supports from the government. In order to promote the development of creative industries, the government should take the lead, found a development fund for creative industries, and apply certain incentives in investment \& financing policies, financial policies, incentive policies, taxation, import \& export, and talent training. Secondly, give tax exemption and deduction, soft loan, and guaranty for important creative enterprises and projects. Besides, guide social capitals to join in creative industries, achieve multiple financing for the development of creative industries.

(4) Strengthen the protection of intellectual property right. Creative industries are based on individual's creativity, techniques, and talents. Its core is innovation and creativity. To protect the intellectual property right is the key for the existence and development of creative industries. And the protection of intellectual property right is equal to the protection of people's creativity and innovative abilities. Therefore, firstly we should enhance the recognition to the importance of protecting intellectual property right and improve the legislation of intellectual property law. We should focus on the enforcement of protection law of intellectual property right, strictly cracking down all piracy activities, building an evaluation system for the development of creative industries, and creating a standard, healthy, and orderly external environment for the development of creative industries by improving the protection of intellectual property right, the application of patents, and the authorization of qualities.

(5) Support the leading enterprises, and promote the integration of industry chain. The core of the development of creative industries is to build a creative industry chain and extend it to form certain scale, achieving the maximum economic benefits. Creative industries are not only the integration of culture and economy, but also the combination of advanced manufacturing and modern service industry. Therefore, creative industries must combine with kinds of factors, such as management, technology, marketing, and culture, and even other industries together, thus creating a market-oriented, complete, and competitive creative industry cluster, driving industry upgrading and improving its international competitiveness.

(6) Build own brands, and emphasize on localization. China has rich cultural heritage and long history, with unique culture resources in the world. If Chinese creative products have no Chinese special features, they can not match the "China" label. However, most Chinese culture resources can not directly become competitive products in the international culture market. We must re-develop and re-create creative products according to main international market requirements. Creative industries can transform Chinese culture resources into economic resources. Make products enriched by Chinese culture enter the international market, promote Chinese culture, let the world know China, participate into international competition, and improve China's international competitiveness.

Besides, we should vigorously develop small and medium-sized enterprises, build and improve a public service platform for creative industries. The government should offer policy and financial supports for flexible and creative small and medium-sized enterprises.

Today with the growing trend of globalization and increasingly fierce international competition, the development of creative industries has become an important indicator evaluating the comprehensive competitiveness of one country or city. China has relatively poor natural resources, a large population, and absolutely rich culture resources. To develop culture creative industries is undoubtedly a wise move to play up strengths and avoid weaknesses, which will produce great and powerful contribution to the practice of scientific outlook on development

\section{References}

Li, Jianjun. (2008). Review of creative industry research progress. The Border Economy \& Culture, No. 3. p97-98.

Li, Wuwei \& Wang, Huimin. (2006). Creative industry helps to transform the way of economic growth -----mechanism, mode, and path. China Industrial Economics, No. 11, p5.

Liu, Chuncheng \& Bai, Xufei. (2007). Study on the development policy of cultural creativity industry in Chaoyang region. Economic \& Trade Update.

Qian, Jing \& $\mathrm{Hu}$, bo. (2006). Reference of creativity industry development mode and exploration ------ case study of Shanghai. Economic Tribune, No. 4, p48.

Wu, Changnan. (2006). The development and evolution of world originality industry. Economy Review, No. 9, $\mathrm{p} 48-50$. 